The Dynamic Response of

Thick-Liquid Shielding in Z-IFE Reactors

R. P. Abbott

October 6, 2005

Symposium on Fusion Engineering

Knoxville, TN, United States

September 26, 2005 through September 30, 2005 
This document was prepared as an account of work sponsored by an agency of the United States Government. Neither the United States Government nor the University of California nor any of their employees, makes any warranty, express or implied, or assumes any legal liability or responsibility for the accuracy, completeness, or usefulness of any information, apparatus, product, or process disclosed, or represents that its use would not infringe privately owned rights. Reference herein to any specific commercial product, process, or service by trade name, trademark, manufacturer, or otherwise, does not necessarily constitute or imply its endorsement, recommendation, or favoring by the United States Government or the University of California. The views and opinions of authors expressed herein do not necessarily state or reflect those of the United States Government or the University of California, and shall not be used for advertising or product endorsement purposes. 


\title{
The Dynamic Response of Thick-Liquid Shielding in Z-IFE Reactors
}

\author{
Ryan P. Abbott \\ University of California, Lawrence Livermore National Laboratory, Livermore, United States of America
}

\begin{abstract}
A major concern in the design of thick-liquid protected inertial fusion reactors of all types is the dynamic response of the shielding liquid to the pulsed explosions. Induced liquid motion can stress and damage solid chamber structures such as the firstwall. In a z-pinch based inertial fusion (Z-IFE) reactor this issue becomes particularly critical due to the relatively large proposed target yields of several GJ. In this paper we summarize an analysis of the liquid response taking into account ablation of target facing surfaces, pocket venting, and neutron isochoric heating. The impact of varying several reactor parameters is also discussed.
\end{abstract}

Keywords-fusion; z-ife; flibe

\section{INTRODUCTION}

In Z-IFE reactor designs, the fusion explosion is surrounded by a flowing curtain of the molten salt flibe to shield the solid chamber structures from x-rays, ionized debris, and neutrons. A potential cross-section of this curtain is shown in Fig. 1.

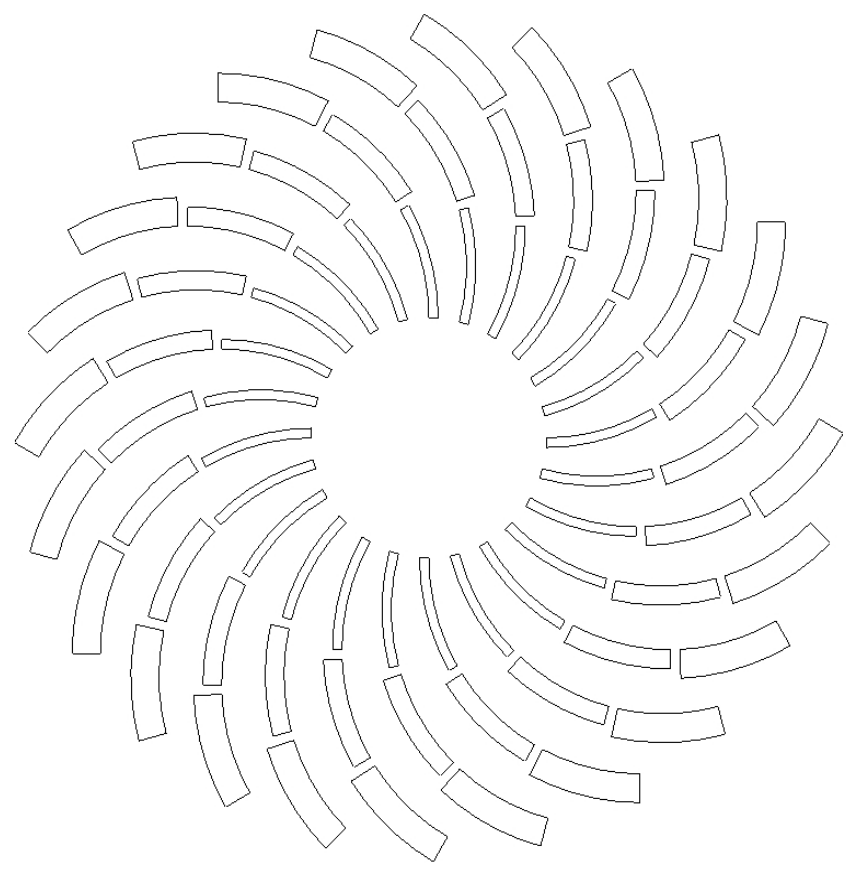

Figure 1. The cross-section of an "enhanced venting" curtain composed of arcing slab jets.
There are three phenomena will that lead to outward motion of the liquid curtain: x-ray ablation of target facing surfaces, form drag on the curtain as vapor vents from the central pocket, and jet breakup due to neutron isochoric heating. This induced outward motion could cause threatening mechanical stresses if the curtain liquid were to impact the first-wall. It is, therefore, important to understand and quantify the dynamic response of thick-liquid shielding in Z-IFE reactors so that the chamber can be designed to avoid such impacts.

The liquid shielding geometry called for in Z-IFE is quite similar to the concepts employed in both the HYLIFE [1] and HYLIFE-II [2] reactor studies. Consequently, much of the analysis previously carried out to understand the dynamics of these chambers can be reapplied. In the sections that follow, we detail qualitatively and quantitatively how each process listed above contributes to the outward motion of the liquid curtain and apply the results to Z-IFE reactor conditions.

\section{LIQUID ABLATION}

About $30 \%$ of the energy released from a Z-IFE target will be in the form of $x$-rays and ionized debris. This energy will deposit in and ablate a thin layer of liquid from all target facing surfaces. This event will apply a strong impulse to the underlying liquid and induce liquid motion toward the firstwall as the ablated plasma rockets toward the center of the chamber.

The first step in quantifying the impulse that will be delivered is to calculate the mass of flibe that will be ablated $\left(\mathrm{m}_{\mathrm{a}}\right)$. Pocket geometry and fusion yield determine the x-ray flux that is delivered to the target facing surfaces. A typical fusion x-ray spectrum will produce the ablation depths given in Fig. 2 [3]. Ablation mass can then be determined by multiplying the appropriate ablation depth and the surface area of the directly exposed inner pocket (A).

Taking $\mathrm{E}_{\mathrm{xi}}$ to be the total target yield in the form of $\mathrm{x}$-rays and ionized debris minus the energy needed to vaporize, disassociate and ionize the ablated flibe, the specific ablation impulse (I) can be shown to be

$$
I=\frac{\sqrt{2 \cdot m_{a} \cdot E_{x i}}}{A} .
$$

Dividing this by the aerial density of the shielding curtain ( $\mu$, the amount of mass for each unit of target-facing surface area) gives the average outward speed induced from liquid ablation $\left(\mathrm{v}_{\mathrm{a}}\right)$ to be 


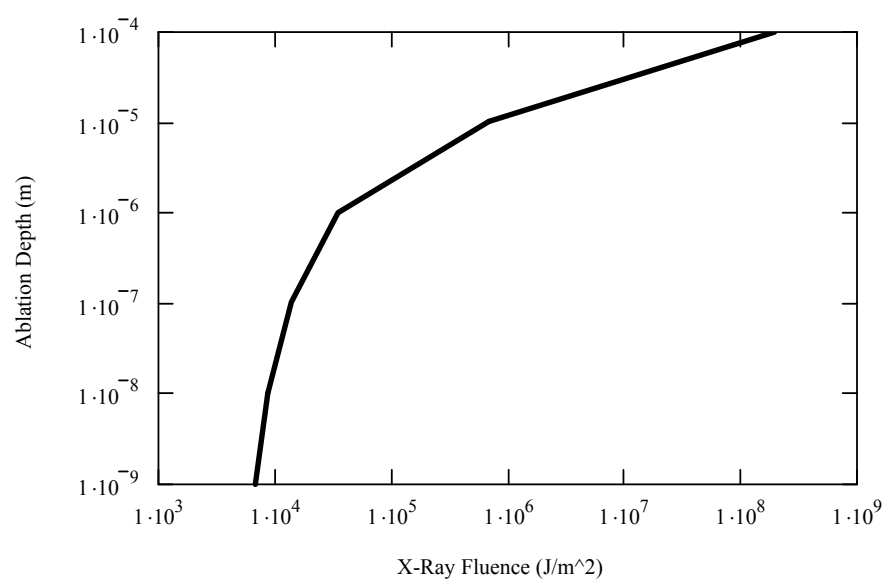

Figure 2. Ablation depth in flibe as a function of $\mathrm{x}$-ray fluence for a typical fusion spectrum.

$$
v_{a}=\frac{I}{\mu} .
$$

\section{Pocket Venting}

After the initial x-ray ablation has occurred, the plasma generated will cool by re-radiating to newly exposed target facing liquid surfaces and vaporizing more flibe. This vapor will then impose a form drag on the liquid curtain as it vents through it over some period of time, thus generating another impulse that will further accelerate the liquid shielding outward.

If the vaporized shielding is assumed to equilibrate at a temperature of $5000 \mathrm{~K}$ before venting begins, $57 \%$ of $\mathrm{E}_{\mathrm{xi}}$ will be used in heating the flibe to its boiling point and inducing its phase change to vapor. The remaining $43 \%$ will go into generating an initial central pocket pressure of

$$
P_{0}=\frac{0.43 \cdot E_{x i} \cdot(\gamma-1)}{V},
$$

where $\gamma$ is the specific heat ratio of the vapor and $\mathrm{V}$ is the volume of the pocket. The amount of additional induced speed from venting $\left(\mathrm{v}_{\mathrm{v}}\right)$ will be

$$
v_{v}=\frac{P_{0} \cdot \tau}{\mu}
$$

where $\tau$ (the venting time constant) is a function of the vapor sound speed, the pocket volume, and the curtain venting area.

\section{NEUTRON ISOCHORIC HEATING}

Glenn [4] has studied the mechanisms by which volumetric deposition of neutrons will impart bulk outward motion to liquid shielding and quantitatively determined the magnitude of that motion. Further, he has shown that this effect will be reduced by $70 \%$ for a segmented annular array due to dissipation by viscous forces [5]. The induced speed from neutrons is then

$$
v_{n}=\frac{0.3 \cdot E_{n} \cdot \Gamma}{C \cdot m},
$$

where $\left(E_{n}\right)$ is the total deposited neutron energy, $(\Gamma)$ is the Gruneisen constant, $(\mathrm{C})$ the liquid sound speed, and (m) the total amount of mass in the shielding curtain.

\section{EFFECTS OF PARAMETER VARIATION}

The final averaged outward liquid speed (v) is then the sum of the velocities induced by the mechanisms described above:

$$
v=v_{a}+v_{v}+v_{n}
$$

Fig. 3 is a normalized plot showing how variation of several key reactor parameters affects the magnitude of this total outward velocity with respect to the baseline Z-IFE reactor design.

\section{RESUTLS FOR Z-IFE}

The baseline Z-IFE reactor design assumes a 3 GJ target yield with approximately $50 \mathrm{~cm}$ of flibe shielding the first-wall. A more aggressive design calls for 4.7 GJ target yields and a reduction in the number of reactors by going to higher repetion rates. To handle the increased neutron fluence, the shielding thickness is increased to $1 \mathrm{~m}$. Table 1 summarizes the outward liquid velocities induced for both of these designs. It is important to note that higher velocities are achieved in the lower yield baseline case due to the reduced curtain thickness.

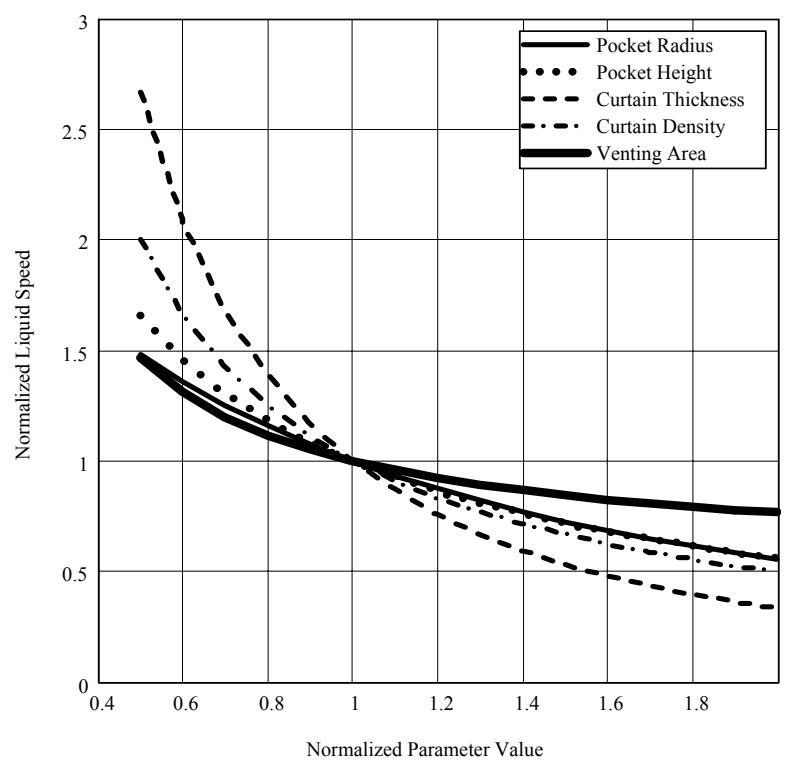


Figure 3. A plot showing how outward liquid velocity varies with various parameters normalized to the baseline Z-IFE reactor design.

TABLE I. SUMMARY OF OUTWARD LIQUID VELOCITES FOR Z-IFE

\begin{tabular}{|c|c|c|}
\cline { 2 - 3 } \multicolumn{1}{c|}{} & \multicolumn{2}{c|}{ Z-IFE Plant Design } \\
\hline Effect & $3 \boldsymbol{G J}$ & $\mathbf{4 . 7} \boldsymbol{G J}$ \\
\hline Ablation & $0.7 \mathrm{~m} / \mathrm{s}$ & $0.4 \mathrm{~m} / \mathrm{s}$ \\
\hline Pocket Venting & $2.8 \mathrm{~m} / \mathrm{s}$ & $1.8 \mathrm{~m} / \mathrm{s}$ \\
\hline Neutron Isochoric Heating & $2.7 \mathrm{~m} / \mathrm{s}$ & $1.8 \mathrm{~m} / \mathrm{s}$ \\
\hline Total & $6.2 \mathrm{~m} / \mathrm{s}$ & $4 \mathrm{~m} / \mathrm{s}$ \\
\hline
\end{tabular}

VII. SUMMARY AND CONCLUSIONS

The average outward velocity of liquid in a Z-IFE reactor due to x-ray ablation, pocket venting, and neutron isochoric heating has been calculated. With knowledge of the fall speed of the liquid curtain, the results of these calculations can be used to determine the nominal deflection angle the curtain will have after a fusion explosion. The reactor first-wall can then be flared appropriately to avoid direct bulk liquid impact and the wall stresses that would result.

\section{ACKNOWLEDGEMENT}

This work performed under the auspices of the U.S. Department of Energy by University of California, Lawrence Livermore National Laboratory under contract No. W-7405Eng-48.

\section{REFERENCES}

[1] J. A. Blink, W. J. Hogan, J. Hovingh, W. R. Meier, and J. H. Pitts, "The high-yield lithium-injection fusion-energy (HYLIFE) reactor," UCRL53559 (1985).

[2] R. W. Moir, R. L. Bieri, X. M. Chen, T. J. Dolan, M. A. Hoffman, P. A. House, R. L. Leber, J. D. Lee, Y. T. Lee, J. C. Liu, G. R. Longhurst, W. R. Meier, P. F. Peterson, R. W. Petzoldt, V. E. Schrock, M. T. Tobin, W. H. Williams, "HYLIFE-II: A Molten Salt Inertial Fusion Energy Power Plant Design-Final Report," Fusion Technology 25 (1994) 5-25.

[3] Moir et al., "HYLIFE-II Progress Report," UCID-21816, p. 4-8, December 1991.

[4] L.A. Glenn, "On the Motion Following Isochoric Heating of Concentric Liquid Annuli," Nucl. Eng. Des., vol. 60, pp. 327-337, 1980.

[5] Moir et al., "HYLIFE-II Progress Report," UCID-21816, p. 4-19 - 4-23, December 1991. 